\title{
FLUORESCEIN TEST OF CIRCULATION TIME IN PERIPHERAL VASCULAR DISEASE
}

\author{
BY \\ ALASTAIR G. MACGREGOR AND E. J. WAYNE
}

From the Department of Pharmacology and Therapeutics, University of Sheffield and Sheffield Royal Infirmary

Received May 25, 1950

There are already many well-established techniques and tests used in the diagnosis of occlusive arterial disease and in evaluating the degree of severity of a given case and the response to therapeutic procedures. A reliable objective measurement of the speed of the blood flow to the extremities would, however, provide additional useful information in the study of peripheral vascular disease, but there has not yet been available a simple test that measures the speed of flow to the periphery of a limb.

Tests of circulation time fall into two main groups - the subjective, which require the co-operation of the patient, and the objective, which are independent of his reactions and of his collaboration. Much American work has been based on a subjective test (Spier, Wright and Saylor, 1936) in which the intravenous injection of a solution of magnesium, calcium, sodium, and copper salts gives to the subject a sensation of warmth in the throat, hands, perinæum, and feet as the solution reaches those areas. Histamine or sodium cyanide have been uséd to give objective end points, but they are unpleasant for the patient and give only a limited amount of information. We have used radioactive sodium $\left(\mathrm{Na}_{24}\right)$ to assess arterial circulation times and to study tissue build-up curves, (Quimby, 1947 ; Elkin et al., 1948) but have found that the method involves technical and administrative difficulties that outweigh its ușefulness, although venous circulation times can be readily and accurately measured with the method (Wright, Osborne, and Edmonds, 1948).

In 1942, Lange and Boyd introduced fluorescein as a test substance; it has the great advantage that it is non toxic, not unpleasant for the patient, and can be detected in very high dilution when the patient's skin and mucous membranes are observed under ultra-violet light. The test as originally introduced enables one to detect, in a given area, the presence of circulating blood containing fluorescein, and an estimate can be made of the time taken for the blood flow between the point of injection and any other chosen part of the skin. The end-point by this method is not sharp, but Nathanson and Merliss (1943) modified the test so that by the use of intradermal histamine wheals the end-point is made to be precise and clear.

We have found the test thus modified to be extremely simple and reliable-a convenient index of peripheral blood flow and of the response to therapeutic procedures. It is, of course, affected by conditions such as heart failure, myxœdema, and hyperthyroidism, but in their absence it gives information about the integrity of the peripheral vessels. It is essentially a measure of the speed of flow to the skin in a chosen area, and as such is influenced by those factors that affect skin flow, the most important of which is skin temperature.

Plethysmography measures more accurately the volume of flow to the limb, and therefore principally to its muscles, but is less readily adaptable to constant routine use and is subject to technical difficulty and error. A test of circulation time can never replace plethysmography but we find that it is a useful index in the routine management of patients with peripheral vascular disease. 
Lange and Boyd (1944) studied patients with peripheral vascular disease and showed how the method can be used to demarcate areas of incipient gangrene. The test has been found to be useful in the investigation of patients with heart failure (Winsor, Adolph, Ralston and Leiby, 1947) and particularly in congenital heart disease in children (Gasul, Marino and Christian, 1949); and in estimating the blood flow in the pedicled skin flaps and tubes used in plastic surgery (Hynes and Macgregor, 1949).

\section{TECHNIQUE}

Observations made on patients with peripheral vascular disease are notoriously subject to variation due to environmental conditions, and Winsor et al. (1947) have shown the effect on the fluorescein circulation test of different environmental temperatures. Past work has suffered through the lack of a recognized standard technique. To be of value the results in patients must be obtained in circumstances that are as standardized and constant as possible.

Our practice is to carry out the test in a room which can be darkened and in as warm an atmospere as is practicable, so that vasodilatation and relaxation of the vessels of the limbs is induced. The patient lies on a couch in a warm room and skin temperature readings are taken of the soles of the feet. Both the patient's arms are then immersed in arm baths containing hot water, about $42^{\circ}$ or $43^{\circ} \mathrm{C}$., for over ten minutes, so that considerable body sweating is induced. Oscillometric observations are made on the patient's calves, and at the conclusion of the ten minutes the skin temperatures are again taken and thereby additional information is gained about the capacity of the vessels to dilate.

Small intradermal wheals are then made with injections of $0.05 \mathrm{ml}$. of a mixture of equal parts of 5 per cent. procaine and $1: 1000$ histamine acid phosphate. The wheals can be placed on any part of the skin to which it is desired to measure the speed of circulation. When investigating the flow to the lower limbs, we produce wheals just above each patella, on the dorsum of each foot just proximal to the base of the middle toe, and at the elbow just beside the antecubital fossa of the left arm.

$4 \mathrm{ml}$. of a 20 per cent. solution of sodium fluorescein is then rapidly injected intravenously at the right elbow, the injection being carried out in the dark under the light of a "Mercra" 125-watt M.B.W./V ultra-violet lamp which has been appropriately filtered in its manufacture so that the radiation emitted is in the range $3130 \mathrm{~A}$ to $4070 \mathrm{~A}$, with 95 per cent. of the radiation concentrated at $3650 \mathrm{~A}$. This is the appropriate lamp to use as the fluorescence of fluorescein is maximal at a wave-length of $3600 \mathrm{~A}$.

The time is measured with a stopwatch from the beginning of the injection until the first appearance of fluorescence in the intradermal histamine wheals previously placed as markers. The endpoint is clear and sharp, and the appearance of the wheals during the test has been likened to the sudden illumination of a small light. The wheals fluoresce with a bright yellow-green fluorescence which contrasts sharply with the initial blue-purple appearance of the surrounding skin. Generalized skin fluorescence can then be observed and its distribution noted. The first appearance of fluorescence in a very ischæmic area takes the form of a green halo surrounding the histamine wheal, the wheal itself remaining as a dark central area. The usual appearance, however, is immediate bright fluorescence of the whole wheal, a fluorescence that extends along the pseudopodial extensions of the wheal.

The following measurements are made: the time is taken from the beginning of the injection until the first appearance of fluorescence in the wheal at the antecubital fossa of the left arm. This represents the time taken for blood to travel from the right to the left arm, and is termed the armtime. Similarly the time is measured until fluorescence appears in the wheals at the knees (kneetime) and on the dorsa of the feet (foot-time). The difference between the foot and arm times is called the foot-minus-arm-time, and is the most useful index as it eliminates the variables of the pulmonary circulation, and measures the speed of flow in the arterial segments of the lower half of the body. 
The patient is warned that he will have a slightly yellow appearance for a few hours and that his urine will be discoloured. In agreement with other observers, we have found that about 4 per cent. of patients experience a transient feeling of nausea after the injection. None have been sick, and the drug appears to have no adverse effect whatsoever on the great majority of subjects. Most patients evince considerable interest in the whole procedure, and many patients willingly subject themselves to frequent observations.

\section{RESULTS}

Normals. The test was performed on fifteen adult persons who were either healthy volunteers or surgical cases with normal vascular systems. In no case was there any evidence of cardiac or peripheral vascular or endocrine disease.

The results are tabulated in Table I, and compared with the normal results published by Winsor et al. (1947), who were principally concerned with the use of the test in patients with congestive cardiac failure. There is a fairly wide range of normal arm-times and foot-times, but we regard a foot-minus-arm-time (i.e. a foot-time minus arm-time) in excess of 13 seconds as being indicative of some cause of circulatory slowing, when the test is performed under standard conditions. In a normal circulation the times to the two feet should be identical.

TABLE I

Fluorescein Circulation Times in 15 Normal Adults under Controlled Conditions

\begin{tabular}{|c|c|c|c|c|}
\hline & & $\begin{array}{l}\text { Arm-time } \\
\text { (sec.) } \\
\text { A }\end{array}$ & $\begin{array}{l}\text { Feet-time } \\
\text { (sec.) } \\
\text { F }\end{array}$ & $\begin{array}{l}\text { Feet-minus- } \\
\text { arm-time (sec.) } \\
\text { F-A }\end{array}$ \\
\hline $\begin{array}{l}\text { Range } \quad . \quad \ldots \\
\text { Mean } \quad . \\
\text { Standard deviation } \\
\text { Standard error }\end{array}$ & $\begin{array}{ll}. & \cdots \\
\cdots & \cdots \\
\cdots & \cdots \\
. & \cdots\end{array}$ & $\begin{array}{l}9-25 \\
16 \cdot 6 \\
\pm 4 \cdot 14 \\
\pm 1 \cdot 07\end{array}$ & $\begin{array}{l}21-35 \\
27.2 \\
\pm 4.06 \\
\pm 1.05\end{array}$ & $\begin{array}{l}8-13 \\
10 \cdot 6 \\
\pm 1.60 \\
\pm 0 \cdot 41\end{array}$ \\
\hline $\begin{array}{l}\text { Winsor et al. (1947 } \\
\text { Range } \\
\text { Mean }\end{array}$ & $\begin{array}{ll}. & . . \\
. & \ldots\end{array}$ & $\begin{array}{l}15-25 \\
18 \cdot 6\end{array}$ & $\begin{array}{l}25-35 \\
28 \cdot 1\end{array}$ & $\begin{array}{l}9-14 \\
9.5\end{array}$ \\
\hline
\end{tabular}

Thyrotoxicosis, Myxodema, Heart failure, and Coarctation of the Aorta. Table II summarizes typical findings in various conditions. All times are accelerated in thyrotoxicosis, which is well illustrated in Case 16, a young woman of 27 with primary thyrotoxicosis. Her circulation times are both rapid, and the acceleration in the foot-minus-arm-time is statistically significant. Conversely, there is a slowing in myxœdema, and where the slowing is from a generalized cause such as myxœdema or heart failure, it is more apparent in the foot-times than in the arm-times, and so is reflected in prolonged foot-minus-arm-times. This is illustrated by Cases 17 and 18 where initially prolonged times were reduced to the normal range after adequate treatment with thyroid.

Times are prolonged in congestive failure, as shown by Winsor et al. (1947), and by Cases 19 and 20. Case 20 was an elderly patient of 68 with congestive heart failure and gangrenous charges in his right foot due to diabetes, changes that were reflected in the more prolonged times to his right foot. Case 21, with coarctation of the aorta, showed normal arm-times with very prolonged foottimes, a finding that is due to the longer course the blood to the lower half of the body has to travel through the collateral channels. Case 22 is interesting, a patient of 42 with thyrotoxicosis who had the right leg amputated for thromboangiitis obliterans five years previously; his arm-time was in the low normal range, and his left foot-time was also in the normal range; his foot-minus-arm-time was prolonged to 15 seconds, a significant prolongation due to the presence of occlusive arterial disease in his remaining leg. 
TABLE II

Fluorescein Circulation Times in Miscellaneous Conditions

\begin{tabular}{|c|c|c|c|c|}
\hline Case No. & $\begin{array}{l}\text { Arm-time } \\
\text { (sec.) } \\
\text { A }\end{array}$ & $\begin{array}{l}\text { Feet-time } \\
\text { (sec.) } \\
\text { F }\end{array}$ & $\begin{array}{l}\text { Feet-minus- } \\
\text { arm-time (sec.) } \\
\text { F-A }\end{array}$ & Remarks \\
\hline 16 & 12 & 17 & 5 & Thyrotoxicosis. \\
\hline 17 & $\begin{array}{l}15 \\
14\end{array}$ & $\begin{array}{l}64 \\
27\end{array}$ & $\begin{array}{l}49 \\
13\end{array}$ & $\begin{array}{l}\text { Myxœdema. Before treatment. } \\
\text { After one month's treatment with thyroid. }\end{array}$ \\
\hline 18 & 21 & $\begin{array}{l}39 \\
27\end{array}$ & $\begin{array}{l}18 \\
10\end{array}$ & $\begin{array}{l}\text { Myxodema. Before treatment. } \\
\text { After } 10 \text { weeks' treatment with thyroid. }\end{array}$ \\
\hline 19 & 24 & 52 & 28 & Congestive failure. \\
\hline 20 & 34 & $\begin{array}{l}69 \text { (right) } \\
41 \text { (left) }\end{array}$ & $\begin{array}{l}35 \\
17\end{array}$ & $\begin{array}{l}\text { Congestive failure. } \\
\text { Diabetes. Gangrenous changes in right foot. }\end{array}$ \\
\hline 21 & 17 & 43 & 26 & Coarctation of aorta. \\
\hline 22 & 12 & 27 & 15 & $\begin{array}{l}\text { Thyrotoxicosis. Left leg only, right having } \\
\text { been amputated for thromboangiitis obli- } \\
\text { terans. }\end{array}$ \\
\hline
\end{tabular}

Peripheral Vascular Disease. The test has been applied to patients with peripheral vascular disease, and the summarized results are presented in Table III. The patients, in whom the presenting symptom was usually intermittent claudication, had clinical evidence of occlusive arterial disease, with poor arterial pulsations, delayed reactive hyperæmia and impaired oscillometric readings.

TABLE III

Fluorescein Circulation Times in 30 Patients with Occlusive Arterial Disease

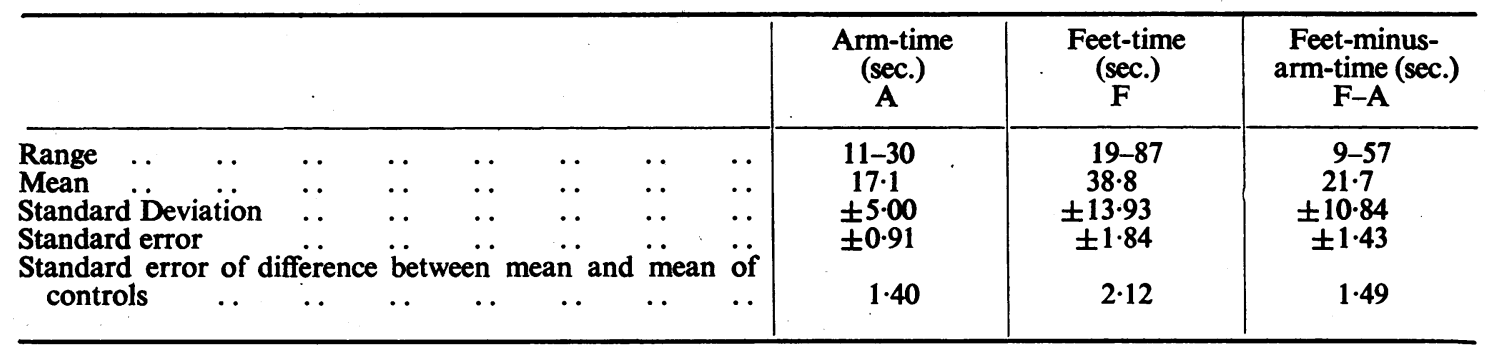

The group consists of 30 patients, with a total of 57 legs, 3 having previously been amputated because of vascular disease. The mean arm-time corresponds closely with the time observed in the control series, but there is a prolongation in the mean foot-time, which is statistically significant, and also in the foot-minus-arm-time, which is highly significant. Five patients of the group (17\%) had normal foot- and foot-minus-arm-times, despite the unequivocal presence of occlusive arterial disease, an observation also noted by Kvale and Allen (1939). In two of these, however, the times to the two feet were unequal, a finding inconsistent with a normal circulation, as the objective demonstration of a difference in the foot-times is by itself evidence of arterial disease. Five other patients had normal foot- and foot-minus-arm-times to one limb, with prolongation to the other; in each case the prolongation was in the limb in which there were symptoms, and in which there was most objective evidence of disease. The criterion of normality for the purpose of these observations was taken as a foot-minus-arm-time of 13 seconds or less. 
TABLE IV

Fluorescein Circulation Times in Patients with Thrombophlebitis Migrans

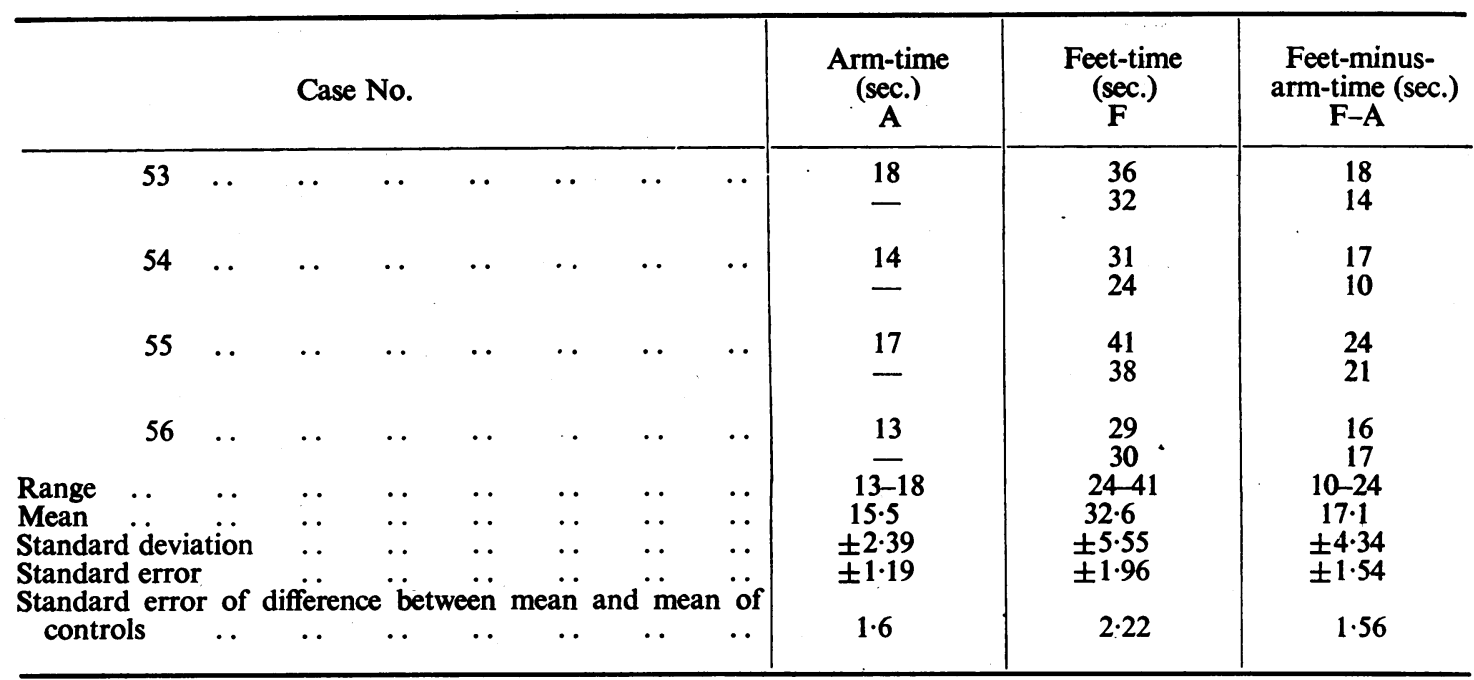

We have not included knee-times in any of the tables. This is a less useful measurement, and even where there is considerable disparity in the times to the feet, the knee-times are usually almost identical on the two sides. Only in the presence of fairly gross femoral artery disease is there a relative slowing of the knee-times on that side.

The test has also been applied to four patients each of whom had presented with the clinical picture of transient and shifting thrombophlebitis, and in no case was there any clinical evidence of arterial involvement (Table IV). The results show a prolongation of the mean foot-times to an average of 33 seconds. This is barely significant in this small group. The foot-minus-arm-times, however, were prolonged to a mean value of 17 seconds, which is statistically significant. It is of interest that the foot-minus-arm time of this group of 4 patients was only below the level of 13 seconds in one of the eight limbs concerned. Case 53 has since he was first tested, recently developed intermittent claudication affecting the right calf, a symptom accompanied by the objective demonstration of more prolonged circulation times on that side.

\section{EFFECTS OF THERAPY}

Table $\mathrm{V}$ lists the results of a series of observations on the immediate effects of various forms of therapy on a man of $\mathbf{4 5}$ with thromboangiitis obliterans. His symptoms were, at first, chiefly in the right leg, although there was objective evidence of a poor flow in both feet. In the initial control observations there was a reasonable degree of agreement in the times, and a feature was the constant difference of 6-9 seconds between the circulation times to his two feet. Observations were made on two occasions following the intravenous injection of tetra-ethyl ammonium bromide (TEAB). The only effect was a slight prolongation of all times, due to the fall in blood pressure. This left the foot-minus-arm-times, and the difference between times to the two feet unaltered. The oral administration of $100 \mathrm{mg}$. of nicotinic acid and the intravenous injection of 1 grain of papaverine hydrochloride had no appreciable effect on the times (not tabulated):

The test was carried out one hour after the intravenous infusion of $200 \mathrm{ml}$. of 3 per cent. saline. This resulted, in this patient, in an acceleration of all his times, but left the difference between the times to his feet constant. When the test was performed 24 hours after right procaine paravertebral block, the difference between his foot-times was reduced to only 3 seconds, and following right 
TABLE V

Effect of Therapy on Fluorescein Circulation Times in Thromboangitis Obltterans

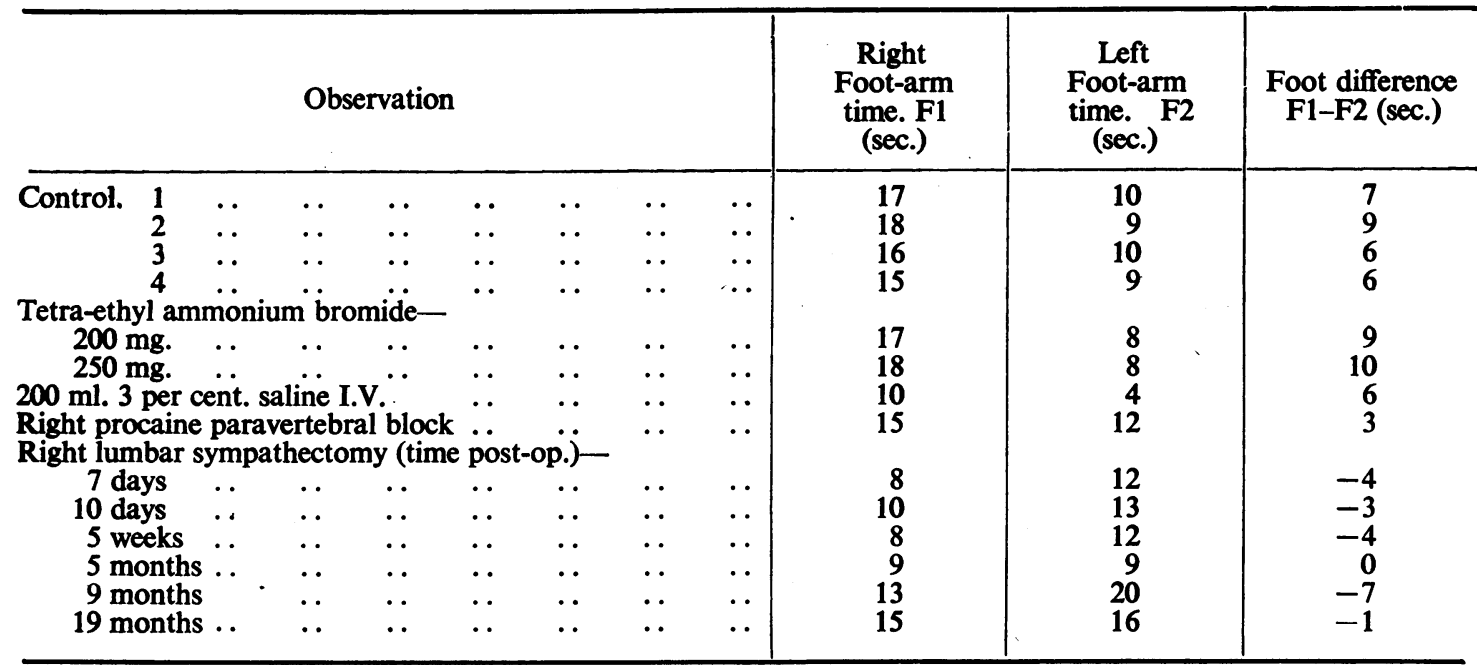

lumbar sympathectomy all post-operative observations showed the difference between his feettimes to be reversed, the circulation time to the foot on the sympathectomized side being quicker than that to the other foot. The most recent observations showed a further increase in the times to the left, untreated foot, an increase that accompanied the first onset of symptoms referable to that foot.

Effect of lumbar sympathectomy.-The test has been carried out before and one week after lumbar sympathectomy had been performed on a series of patients with occlusive arterial disease. In every case an absolute acceleration occurred to the foot on the sympathectomized side. We have found that a useful index of the result of the operation is the degree of acceleration that results relative to the time to the foot on the untreated side. Usually, before operation the foottime on the treated side has been longer than that to the untreated side, whereas after operation the time has been shorter. We have termed the resulting acceleration the relative acceleration, and in a series of 13 operations the mean relative acceleration was 17 seconds. Table VI summarizes these results.

This acceleration is fairly permanent, and the resulting quicker time to the foot persists over periods of months or years, although further organic change may occur in the vessels and alter the absolute time to the two feet. A small series of cases has been tested up to 3 years after operation and, although the times before are not known, where the time to one foot is quicker than that to the other, the quicker time has generally been on the side previously sympathectomized.

This acceleration is undoubtedly related to the rise of skin temperature that results on the treated side, a rise that is persistent and may last many years.

\section{The Relationship of Skin Temperature to Circulation Rate}

As we have pointed out, the observers who have used this test have often failed to standardize the conditions under which readings were made. Full dilatation of the peripheral vessels is essential if observations made on different occasions are to be strictly comparable. It is true that somewhat similar information can be obtained by taking readings of skin temperature but this is a technique much better adapted to detect changes occurring during a short space of time.

We carried out observations on a patient who had had a sympathectomy performed on a leg for chronic œdema which had disappeared after the operation and in whom the arterial circulation 
TABLE VI

Effect of Lumbar Sympathectomy on Fluorescein Circulation Times

\begin{tabular}{|c|c|c|c|c|c|}
\hline Case No. & Observation & $\begin{array}{c}\text { Treated Side } \\
\text { Foot-arm time. } \\
\text { F1 (sec.) }\end{array}$ & $\begin{array}{l}\text { Untreated Side } \\
\text { Foot-arm time. } \\
\text { F2 (sec.) }\end{array}$ & $\begin{array}{c}\text { Foot } \\
\text { difference } \\
\text { F2-F2 }\end{array}$ & $\begin{array}{c}\text { Acceleration on } \\
\text { treated side relative } \\
\text { to untreated side. } \\
\text { (sec.) }\end{array}$ \\
\hline $\begin{array}{c}23 \\
24 \\
25 \\
26 \\
28 \\
29 \\
35 \\
36 \\
39 \\
41 \\
\text { (1st side) } \\
\text { (2nd side) } \\
52 \\
62\end{array}$ & $\begin{array}{l}\text { Before } \\
\text { After } \\
\text { Before } \\
\text { After } \\
\text { Before } \\
\text { After } \\
\text { Before } \\
\text { After } \\
\text { Before } \\
\text { After } \\
\text { Before } \\
\text { After } \\
\text { Before } \\
\text { After } \\
\text { Before } \\
\text { After } \\
\text { Before } \\
\text { After } \\
\text { Before } \\
\text { After } \\
\text { Before } \\
\text { After } \\
\text { Before } \\
\text { After } \\
\text { Before } \\
\text { After }\end{array}$ & $\begin{array}{r}25 \\
12 \\
46 \\
4 \\
18 \\
11 \\
14 \\
11 \\
15 \\
11 \\
21 \\
10 \\
18 \\
10 \\
21 \\
10 \\
38 \\
16 \\
48 \\
14 \\
15 \\
8 \\
9 \\
5 \\
13 \\
6 \\
\\
\text { Mean }\end{array}$ & $\begin{array}{r}24 \\
32 \\
24 \\
32 \\
21 \\
31 \\
9 \\
17 \\
12 \\
16 \\
21 \\
17 \\
11 \\
13 \\
12 \\
21 \\
20 \\
15 \\
8 \\
15 \\
14 \\
16 \\
9 \\
6 \\
13 \\
19 \\
\text { tive acceleration. }\end{array}$ & $\begin{array}{r}1 \\
-20 \\
22 \\
-28 \\
-3 \\
-20 \\
5 \\
-6 \\
3 \\
-5 \\
0 \\
-7 \\
7 \\
-3 \\
9 \\
-11 \\
18 \\
1 \\
40 \\
-1 \\
1 \\
-8 \\
0 \\
-1 \\
0 \\
-13\end{array}$ & $\begin{array}{r}21 \\
50 \\
17 \\
11 \\
8 \\
7 \\
10 \\
20 \\
17 \\
41 \\
9 \\
1 \\
13 \\
17 \cdot 3\end{array}$ \\
\hline
\end{tabular}

\section{NoTES}

(1) Cases 24, 35, 41, and 62 were patients with thromboangiitis obliterans ; remainder were arteriosclerotic.

(2) All observations after operation were made 5-7 days after.

appeared to be intact. After vasodilatation produced reflexly the circulation time to the sympathectomized side was much more rapid. This was still true after immersion of both limbs in water at $37^{\circ}$, but at $44^{\circ}$, when local heat had effected full vasodilatation on both sides, the times were equal as would have been anticipated. We conclude that the test gives information about the degree of vasodilatation that can be obtained by physiological means and is specially suitable for assessing the effect of therapeutic procedures.

Pickering (1933) noted that as a rule a limb affected by structural vascular disease was cooler than its fellow ; occasionally, however, the limb with the greater evidence of vascular disease was the warmer, and he suggested that the explanation of this anomaly was probably that in such warm limbs the circulation was maintained by the opening of collateral channels lying particularly in the skin or subcutaneous tissues. Such an explanation would also apply to those few cases in which we found that the fluorescein circulation times were normal in the presence of occlusive arterial disease.

\section{Discussion}

The normal ranges and times quoted by Winsor et al. (1947) are included in Table I, and are of the same order as found in our control series. Kvale and Allen (1939) quote rather longer normal average foot-times than we have found with this technique, but this is because their method, that of Spier et al. (1936), was essentially a subjective one and the figures include the appreciable delay between the time when the test substance reached the patient's foot and his expression of 
his sensation. Similarly, the normal times published for the fluorescein test by Kramer and Abramson (1947) were more prolonged, but were obtained without the assistance of the histamine wheal markers and are therefore unreliable.

The circulation times obtained in patients with occlusive arterial disease are, as one would expect, prolonged, and the vast majority of patients with arterial disease have different times to the two feet.

We feel that the fluorescein test of circulation time, because of its simplicity and objectivity, is worthy of more general use with a standard technique. It certainly provides an objective index of the severity of affection in the majority of cases, and serial observations over a period of years will provide interesting information regarding the development of impaired blood flow in the presence of occlusive arterial disease. We have shown that in cases of thrombophlebitis migrans, in which there is no evidence of arterial disease, there is already a significant prolongation in the difference between foot-time and arm-time. Prolonged times under controlled conditions are significant but normal times do not exclude impaired blood flow in a small minority of patients. The fact that it is possible to obtain normal circulation times when there is undoubted occlusive disease present makes the test less valuable as an absolute diagnostic agent, but all tests used in peripheral vascular disease suffer from the same defect.

In our series of sympathectomized patients, all of whom had evidence of occlusive arterial disease, there has been constantly an acceleration in the speed of flow to the foot on the sympathectomized side, and this acceleration has persisted in those patients who have been repeatedly examined, or have been examined for the first time some months or years after sympathectomy. Objective demonstration of an accelerated blood flow to the sympathectomized limb has been found to be of considerable value in reassuring the patient regarding the result of his operation, and the test provides a useful objective measurement of the effect of lumbar sympathectomy. Its value in measuring the degree of response to other therapeutic procedures designed to increase the flow of blood to the limbs is being further assessed.

\section{SUMMARY}

The time taken for fluorescence to appear in small histamine wheals examined under ultra-violet light has been used as a measure of circulation rate.

The test may be used to study either general conditions in which the circulation rate is affected, such as heart failure and myxœdema, or to investigate peripheral vascular anomalies.

The average normal arm-time in a series of patients was found to be 16.6 seconds, and the average foot-time, 27 seconds. Significant prolongation of all times was usually found in myxœdema and heart failure, and all times were accelerated in hyperthyroidism. The foot-minus-armtimes reflect mainly changes in the peripheral vessels, and figures in excess of 13 seconds were usually due to the presence of occlusive arterial disease, especially when the arm-times were normal. Different circulation times to the two feet were indicative of an abnormal circulation even though the absolute times might be normal. In a minority of cases arterial disease existed when the circulation times were normal.

The test has been used as an objective index of the response to treatment. An average acceleration of 17 seconds relative to the untreated leg occurred in the circulation times to the feet of a series of patients on whom unilateral lumbar sympathectomies had been performed because of peripheral vascular disease.

We wish to thank Dr. J. F. Goodwin for much assistance in carrying out this work, Mr. Clifford Jones, on whose patients many of these observations were made, Mr. D. H. Randall for his co-operation and Dr. G. M. Wilson for his criticism. We are indebted to Mr. A. G. Barritt for his technical assistance. The ultra-violet light source was obtained from the British Thomson-Houston Co. Ltd. 
REFERENCES

Elkin, D. C., Cooper, F. W., Rohrer, R. H., Miller, W. B., Shea, P.C., and Dennis, E. W. (1948). Surg. Gynec. Obstet ., 87, 1.

Gasul, B. M., Marino, J. J., and Christian, J. R. (1949). J. Pediatrics., 34, 460.

Hynes, W., and Macgregor, A. G. (1949). Brit. J. plastic. Surg., 2, 4.

Kramer, D. W., and Abramson, E. B. (1947). Amer. J. med. Sci., 214, 368.

Kvale, W. F., and Allen, E. V. (1939). Amer. Heart J., 18, 519.

Lange, K., and Boyd, L. J. (1942). Med. Clin. N. Amer., 26, 943.

- (1944). Arch. intern. Med., 74, 175.

Nathanson, M. H., and Merliss, R. (1943). Proc. Soc. exp. Biol., 53, 261.

Pickering, G. W. (1933). Brit. med. J., 2, 1106.

Quimby, E. H. (1947). Amer. J. Roentgenol., 58, 741.

Spier, L. C., Wright, I. S., and Saylor, Leslie (1935). Amer. Heart J., 12, 511.

Winsor, T., Adolph, W., Ralston, W., and Leiby, G. M. (1947). Ibid., 34, 80.

Wright, H. P., Osborne, S. B., and Edmonds, D. G. (1948). Lancet, 2, 767. 